\title{
En busca del sentido perdido. De la religión y la utopía al paraíso del consumo
}

Adrián Huici | ahuici@us.es

UNIVERSIDAD DE SEVILLA

Resumen: Este artículo intenta mostrar cómo dos de los grandes relatos de legitimación individual y social como lo fueron, en el ámbito de la cultura occidental y durante siglos, la religión cristiana en sus distintas variantes y el pensamiento utópico, con su articulación en los sistemas políticos del llamado "realismo socialista" o "comunismo", han perdido peso y su categoría de referente ético, de Weltanschauung o modelo de conducta, han dejado de influir en las grandes masas, como lo hicieran en su momento.

Puesto que el hombre no puede prescindir ni de la categoría de lo sagrado, ni de la de esperanza en el progreso social (representadas por la religión y la utopía), el sistema capitalista ha realizado, con la inestimable colaboración de la publicidad, la operación de presentar al consumo como "teología de sustitución" de ambas categorías. Todo ello implica un ataque a la razón y un regreso a lo irracional, en las antípodas del pensamiento ilustrado.

Palabras clave: Utopía, religión, consumo.

Abstract: This paper tries to show how two of the great individual and social legitimation tales (in the realm of western culture, and existing for centuries), Christian religion (in its different forms) and utopian thought (with its political correlates, the so called "socialist realism" or "communism"), have zlost relevance as well as their quality of ethical referent, Weltanschauung, or behaviour pattern. They have also stopped influencing great masses of people.

Man cannot do without the category of the sacred, nor the hope about social progress. Both are represented by religion and utopia. Hence, capitalism (with the collaboration of advertising) has displayed consumption as a "substitution theology" of both categories. All this implies an attack on reason and a return to the irrational, very far away from the Enlightenment.

Key words: Utopia, religion, consumption. 
A lo largo de los siglos se han postulado innumerables definiciones del hombre, buscando un universal antropológico común a toda la humanidad. Surgen así los diferentes "homos": sapiens, loquens, religiosus o symbolicus, por no hablar del aristotélico y certero zoon politikón. A pesar de esta proliferación conceptual, creemos que estos términos son en realidad complementarios y, además, pensamos que todos ellos pueden subsumirse en un solo concepto, más amplio y abarcador, que es el concepto de sentido el que, por otra parte, -y siempre desde nuestro particular punto de vista- estaría en el origen, como causalidad, de la producción humana del lenguaje, la religión, los símbolos o la sociabilidad.

El hombre es un animal sediento de sentido, con la aguda necesidad de que su existencia y el mundo al que ha sido arrojado, estén dotados de un significado y exhiban un orden determinado que lo pongan a cubierto del caos. Necesitamos que la realidad exhiba un significado concreto que, a su vez, permita atisbar una finalidad para nuestras vidas, en otros términos: un sentido.

Para ello, el animal humano se emplea a fondo para que el mosaico de lo real encaje en marcos cognitivos y conceptuales de modo que pueda sustraerlo de lo indefinido, de lo indeterminado y de lo que está fuera de un orden concreto, es decir, de lo que cae en el absordo ("no orden", en latín): en el absurdo, que es lo incomprensible e injustificable, por desordenado, por caer fuera de toda regla o límite, aquello que, precisamente por no estar sujeto a la racionalidad de la ley y la norma, tiende al caos, a la disolución y al desorden, es decir, a la desorganización, que son otros tantos nombres con los que la física, primero, y la Teoría de la Comunicación, más tarde, definen la entropía. Esa tendencia de todo lo existente al caos, a la disolución de toda diferencia y determinación, lo cual en los seres vivos es sinónimo de muerte.

La tendencia opuesta a la entropía se denomina "neguentropía”, y su metáfora más representativa para nuestro imaginario colectivo, es la cosmogonía, tal y como aparece en casi todas las religiones y, particularmente, en el Génesis, donde se parte, precisamente, de una posición de caos y de tinieblas, es decir, una situación en la que no se pueden distinguir formas (elementos in-formados) ni funciones. El acto creador (la neguentropía) consiste, precisamente, en separar, en distinguir (cartesianamente hablando) y nombrar para aprehender y comprender, para que lo que una vez fue caos e indeterminación, tenga ahora significado y, por añadidura, sentido.

No es casual que hayamos buscado un ejemplo extraído de las religiones, porque fue a través del mito y del pensamiento mágico, primero, y luego de las religiones, como el hombre dio sus primeras batallas por el sentido y contra las fuerzas del caos y la disolución, contra la entropía o, si se prefiere un lenguaje más crudo, contra la muerte.

Por tanto, la religión nos proporciona los elementos necesarios par conjurar la amenaza del sinsentido, del sentimiento del absurdo y del vacío existencial que, con gran perspicacia, Freud identificó con "la falta": ese sentimiento de incompletitud, de insatisfacción 
permanente, de vacío que nunca parece llenarse, hagamos lo que hagamos y tengamos lo que tengamos.

Si nos remitimos al ámbito del Occidente cristiano, se puede decir que durante muchísimos siglos, la religión ha cumplido, casi sin rivales, con la tarea de llenar ese vacío, de proporcionar sentido a nuestras vidas, justificación y legitimación social, de modo que podemos afirmar que se puede identificar con la función atribuida a la ideología.

Obviamente, no vamos a entrar aquí en la larga e interminable discusión acerca de la definición de ideología. Sólo diremos, para fijar un terreno de entendimiento común, que seguimos a Terry Eagleton (1997) y a Paul Ricoeur (1990), quienes consideran que la ideología es un discurso que viene a cumplir con tres funciones, cada una de ellas imbricada con las otras dos. La ideología, en su acepción más neutra, es Weltanschauung, una determinada visión del cosmos, una forma personal y colectiva de entender al hombre y al mundo y, por tanto, de conferirle sentido. Lo que no hace sino confirmar su parentesco con la religión. En segundo lugar, la ideología puede entenderse como un discurso de legitimación del orden social y del sistema vigente. Que es lo que hizo la religión en Occidente, al menos hasta los inicios de la Modernidad: erigirse en árbitro sancionador y en instancia legitimadora, que por estar sustentada en un plano metafísico, externo a la sociedad, se considera heteronómica. Frente a esta situación, a partir del Renacimiento se inicia la conquista de la autonomía, es decir, la situación en que es la propia sociedad, “desde dentro", la que se provee de sus propios mecanismos de legitimación, circunstancia, ésta última, que seguramente está en el origen del poco entusiasmo que la Modernidad despierta en el seno de la jerarquía eclesiástica, incluso hasta nuestros días ${ }^{1}$.

En tercer lugar, llegamos a la definición de ideología como "falsa conciencia", atribuida al joven Marx. Se trata de la definición más negativa ya que designa al discurso ${ }^{2}$ utilizado por la élite dominante para perpetuarse en el poder. Un discurso engañoso que genera aceptación y sumisión y que algunos, desde posturas radicales, consideran que es, precisamente, la tarea desempeñada por las religiones institucionalizadas que perpetúan las relaciones de opresión con la promesa de otro mundo al que se accede como premio a los sufrimientos padecidos en éste.

Por otra parte, se podría decir que la ideología padece una especie de horror vacui, esto es, que busca su aceptación por la mayor cantidad de gente posible como condición de existencia por lo cual requiere ser difundida y propagada, es decir, que necesita de esa forma de comunicación persuasiva llamada "propaganda". Pues bien, no sólo resulta pertinente tener en cuenta aquí el carácter misionero del cristianismo, ello desde su primer momento: apóstol es "el que se envía lejos a predicar", sino que debemos recordar que el

\footnotetext{
${ }^{1}$ Al respecto, vid. Ferry, L. y Gauchet, M. (2007: passim)

${ }^{2}$ Utilizamos este término porque, siguiendo a van Dijk (1998), entendemos que la ideología es en principio, aunque no solamente, un caso discursivo.
} 
concepto de propaganda, tal y como lo utilizamos hoy, tiene su origen en el mismo seno de la Iglesia Católica, en el contexto de su lucha contra la Reforma luterana ${ }^{3}$.

Precisamente, la Reforma protestante y la aparición del humanismo, con el famoso discurso sobre la dignidad del hombre de Picco de la Mirándola como emblema máximo del ascenso del sujeto y el cambio de paradigma científico, es decir, todo aquello que conforma la Modernidad, será lo que comience a cuestionar no sólo la hegemonía política de la religión institucional, sino su papel como dadora de sentido $y$, consecuentemente, su función legitimadora y organizadora del orden social basado en la heteronomía a la que ya nos hemos referido.

Al respecto, es fácil estar de acuerdo con los filósofos Luc Ferry y Marcel Gauchet (2007: passim), que entienden la democracia como sistema que representa la culminación política de la Modernidad puesto que no requiere de fundamentos basados en ningún absoluto ni en ninguna trascendencia.

Por lo tanto, es correcto asociar Modernidad, en tanto que aplicación del método científico y confianza en la razón como el instrumento básico del progreso de la humanidad, no sólo con la democracia sino con el proceso de secularización y laicización, que cuestionará la religión hasta relegarla al territorio de lo privado y consagrará la separación de la Iglesia y el Estado. De hecho, algunos pensadores de entre siglos, notoriamente el sociólogo Max Weber (2000), llegaron a hablar de la "jaula de hierro de la razón” en la cual quedaría definitivamente encerrada la religión.

Sin embargo, tanto Ferry como Gauchet coinciden en recordarnos que ni siquiera el homo democraticus, tanto a nivel individual como colectivo, puede prescindir de una cierta noción de trascendencia, a la que podríamos denominar religión y que, en el caso de la polis, se conoce como "religión civil", definida por Salvador Giner (1994: 133) como

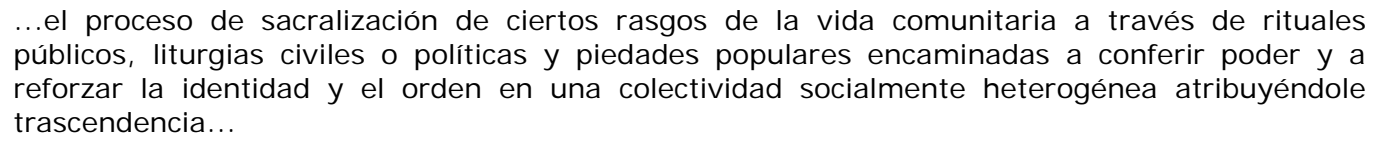

Esta transferencia de lo simbólico y lo sagrado como instancia de sentido se "hará fuerte" durante mucho tiempo en un tipo de pensamiento, en una formulación del imaginario colectivo, que se conoce con el nombre genérico de utopía a la que, en una afortunada expresión, Fraçois Laplantine (1977) denominó: “categoría antropológica de la esperanza” y que se plasmará, en el siglo XIX y parte del XX en movimientos políticos concretos, como el primer socialismo (antes de Marx y la Primera Internacional), el anarquismo o el comunismo, con resultados desiguales en su aplicación práctica, pero con una enorme influencia política.

\footnotetext{
${ }^{3}$ Para ampliar esta cuestión puede consultarse el manual de historia de la propaganda de Alejandro Pizarroso (1993)
} 
En efecto, el pensamiento utópico tomó el relevo, al menos para sectores importantes de la población, de la función que hasta el siglo XVI había tenido la Iglesia en la producción y administración del sentido y de la legitimidad social. $Y$ aunque las manifestaciones más visibles y operantes de la utopía se dan, como lo hemos dicho, a finales del XIX y principios del $X X$, sus comienzos se remontan a Platón, aunque durante el Renacimiento se va a consolidar como fenómeno social y literario. Es, precisamente, en este período histórico cuando comienza a manifestarse la utopía como expresión, tímida, alegórica, prudentemente indirecta, de descontento respecto a las instituciones sociales, especialmente la Iglesia cuya praxis cotidiana parece alejarse cada vez más de las fuentes evangélicas, a lo que debemos sumar (en este proceso de resquebrajamiento de lo que había sido una institución monolítica), su obcecación en el rechazo del paradigma copernicano, su implicación en las terribles guerras de religión, la Inquisición, etc.

Es en este contexto en el que aparecen los utopistas del Renacimiento y de siglos posteriores, como Tomás Moro, que sienta las bases de lo que llegaría a ser un género literario, con su Utopía, Tommaso Campanella, con La Ciudad del Sol y Francis Bacon, con su Nueva Atlántida (1992).

Dice el teólogo Juan J osé Tamayo (1987: 151) que la utopía de Tomás Moro:

\footnotetext{
...ha sido considerada, y con razón, como uno de los más poderosos símbolos a través de los cuales el hombre ha sido capaz de expresar su esperanza en el futuro, hasta poder afirmar que es tan homo utopicus como homo faber y homo sapiens.
}

Y más adelante, este teólogo, comprometido con la opción por los oprimidos y alejado de la jerarquía, nos recuerda que los utopistas del Renacimiento son los primeros en expresar el rechazo al mundo que estaba siendo configurado por el capitalismo naciente:

Los utopistas detectan cómo en la nueva economía la ganancia pasa a ser el motor de la historia y ven en la propiedad privada la causa de la desigualdad reinante y la explicación de las nuevas condiciones degradantes de la vida. (152)

Hemos hecho notar más arriba que, aun en las sociedades democráticas más secularizadas, la propensión humana a la religión nunca desaparece del todo en tanto que la necesidad de trascendencia parece inscrita en la propia naturaleza del hombre. Lo mismo puede decirse del discurso utópico, a pesar de sus elementos anticlericales, ya que su referencia a los principios básicos del cristianismo evangélico son más que evidentes. Existe un componente religioso en el pensamiento utópico pero, en clara simetría, también podemos detectar elementos utópicos en las fuentes primitivas del cristianismo. De allí que no sea casual que un teólogo, como el ya citado, dedique su atención a esta cuestión que podemos denominar como religión de la utopía y utopía de la religión. Lo mismo ocurre con Raymond Trousson, quien en su obra de referencia Historia de la literatura utópica (1999: 19-20) reconoce que, aunque la utopía busca la felicidad en la tierra, ello no le impide reconocer la utilidad de la religión como cemento social. 
Tampoco es casual que los antecedentes más lejanos de los llamados Nuevos Movimientos Religiosos o religiones alternativas, que proliferan hoy, esto es, la gnosis renacentista, la primera teosofía, etc., sean consideradas por F. Lenoir (2005: 205), en consonancia con lo apuntado por Tamayo respecto a la utopía, “...como el primer signo de una protesta social contra el capitalismo naciente", un sistema económico y político, una ideología basada en el beneficio, la acumulación y la cuantificación que congregará a su alrededor al pensamiento conservador y a la incipiente burguesía, que rápidamente va a ocupar el lugar dejado vacante por la aristocracia (recordar el origen del término "snob": sine nobilitate) mientras que el pensamiento utópico se va a situar a la izquierda.

Dice Raúl Eguizábal (2007:204) en su último y excelente libro Teoría de la Publicidad que

Cada estructura de poder mantiene un discurso encargado de servirle y perpetuarle. La propaganda sirvió a los intereses del poder establecido en el pasado: la Iglesia y la nobleza. La burguesía, convertida en clase dominante, necesitaba también de un discurso que defendiese sus intereses: los intereses económicos. Este discurso se conoce como publicidad.

Propaganda, primero, y publicidad, después, van a constituir los dos discursos dominantes en la escena pública y no siempre estarán claramente diferenciados, ni en lo formal, ni en las estrategias persuasivas ni, mucho menos, en lo ideológico.

Ya hemos visto cómo la Iglesia, por su carácter misional, primero, y por su enfrentamiento con la Reforma, más tarde, dará impulso a la exploración y utilización de distintas formas de comunicación persuasiva, que ella misma denominará propaganda: técnicas de predicación, utilización de la "escenografía” proporcionada por la liturgia y la arquitectura, apelación a la imagen y a la imaginería como arma persuasiva de primera clase y frente a la parquedad icónica protestante, etc.

No descubrimos nada si decimos que existe una línea de continuidad entre la fastuosidad de la I glesia de la Contrarreforma y los grandes espectáculos de masas, ahora con el invalorable apoyo de la televisión, instituidos por Juan Pablo II y, al parecer, proseguidos por su sucesor. Propaganda a la que podríamos denominar religiosa, pero que como resulta obvio, no está exenta de carga política (como no lo está la propia Iglesia), ni publicitaria ya que, especialmente en la época presente, el discurso religioso ha echado mano de estrategias propias de los anuncios comerciales, a la vez que también ha tomado una clara deriva hacia el glamour, más propio de las estrellas de Holliwood. Desde el ascenso de Wojtyla al papado, nos hemos acostumbrado a grandes concentraciones de masas, a multitudes de jóvenes histéricos que recuerdan más bien al público de los conciertos de rock, eslóganes y canciones pegadizas al estilo de los jingles publicitarios y, a menudo, lindantes con la trivialidad de las canciones de verano (totus tuus, "Juan Pablo Segundo, te quiere todo el mundo", etc.), omnipresencia de la televisión, vestimentas lujosas, inclusive “de marca”, papamóvil, etc. Es decir, show, espectáculo, visibilidad que, en el caso de la enfermedad y muerte del anterior papa llegó casi a la obscenidad exhibicionista. Por ello, el malogrado teólogo y filósofo de las 
religiones José María Mardones (2000: 64), hace un tiempo, escribía amargamente sobre esta cuestión:

\begin{abstract}
...la espectacularización de las visitas del papa, el tratamiento televisivo como gran hombre o "estrella" lo introduce (a Juan Pablo II) dentro del "star system" y devalúa su mensaje. Este no es oído. En el límite, vale la presencia, el que se dirige a nosotros y nosotros estamos cerca, asistimos y nos sumergimos en el espectáculo de lo sagrado. Pero el contenido de lo que dice, el mensaje es devorado por el ambiente, la circunstancia, la vivencia de la presencia escenificada.
\end{abstract}

La Iglesia toma elementos de la publicidad y la publicidad, a su vez, se aprovechará de esa propensión humana hacia lo sagrado y lo trascendente para incorporarlos como estrategia persuasiva. En un artículo definitivo para dilucidar esta relación mutua llamado, precisamente, “Publicidad y religión” (2006: 77 y ss), Juan Rey demuestra exhaustivamente este "cruce discursivo" y expone con claridad meridiana no sólo las estrategias retóricas sino también las cuestiones ideológicas que, a poco que se aplique el pensamiento críticoracional, surgen de ambos discursos. Entre otros recursos compartidos, el autor menciona: el uso de la imagen, la promesa del paraíso, la obsesión por la limpieza/pureza (estrechamente vinculada con el tema del pecado y la culpa), la dramatización, la utilización de estereotipos y de figuras arquetípicas, el reciclaje de las fiestas, etc.

También el pensamiento utópico va a apelar a diversas estrategias comunicativas para difundir su ideario, empezando por la propia literatura utópica inaugurada por Tomás Moro. Por lo demás, las ideologías de izquierdas que lo heredan comprenderán igualmente que la propaganda, tal y como la utiliza la Iglesia, es un instrumento imprescindible de la lucha política, tanto en la utilización de la imagen como en la apelación a los nuevos medios técnicos puestos al servicio de la comunicación. De hecho, el propio Lenin recomendará a sus propagandistas que, en la tarea de persuadir al proletariado, no han de utilizarse complicadas argumentaciones, propias de los textos marxistas, sino “imágenes vivas y coloreadas".

Sin embargo, a pesar del poder que los nuevos medios y técnicas comunicativas añadieron tanto a la Iglesia como a las ideologías utópicas, el siglo XX contemplará, en ambos casos, una notoria pérdida de influencia, hasta el punto de que podemos hablar de desprestigio y, en el caso de la utopía, de desaparición.

Respecto a la Iglesia, podemos decir que el siglo XX (con la sola excepción de la breve primavera del Vaticano II) no hace sino agudizar su vieja crisis con circunstancias tales como la connivencia del papa Pío XII con el nazismo, la corrupción económica que saltó a la escena pública después de la no demasiado aclarada muerte de Juan Pablo I, la negativa a aceptar adelantos científicos vinculados con la salud o el bienestar de las personas (investigación con células-madre, fecundación in vitro, etc.), rechazo de las técnicas de contracepción, represión de la Teología de la Liberación, excesivo apego a las instancias del poder terrenal, etc. 
En cuanto a la utopía, también ella o, mejor dicho, sus manifestaciones políticas, como el anarquismo, el socialismo o el comunismo, ha perdido credibilidad, algo que se puso claramente de manifiesto en la llamada literatura distópica, inaugurada a principios del siglo XX por Zamiatin (Nosotros), y continuada por Huxley (Un mundo feliz) y Orwell (1984)

El siglo XX asociará algunos de sus más grandes horrores (pero no los únicos) a los sistemas y partidos que se dicen herederos del pensamiento utópico. Los procesos stalinistas de los años treinta, el GULAG, el aplastamiento de los movimientos democratizadores en Hungría y Checoslovaquia, el muro que separó la ciudad de Berlín durante décadas, etc., todo ello fue erosionando el llamado "socialismo real", a lo cual hay que agregar la acción de los Estados Unidos, que con la carrera armamentística y espacial, más su acción propagandística durante la guerra fría, condujeron al derrumbe del Muro de Berlín como gran metáfora del fin de la utopía socialista.

Así, podemos ver cómo la sociedad occidental, especialmente en el siglo XX y después de la Segunda Guerra Mundial, pierde dos de sus grandes fuentes de legitimación y sentido. Y puesto que, como hemos insistido ya muchas veces, el hombre no puede prescindir de ellos, irá a buscarlos a otra parte, o le serán oportunamente ofrecidos por el gran beneficiario de esta pérdida de referentes: la enésima versión del capitalismo, siempre camaleónico, siempre adaptativo.

En otras palabras, se produce una situación de orfandad de sentido, muy poco mitigada por la ideología neoliberal en sí misma, mucho más dispuesta a apoyar a los ganadores, a los que, mientras dure su bonanza, no parecen sentir con tanta agudeza el vacío que sí aqueja a aquellos que, según la ideología de los Friedman y compañía, no han hecho lo suficiente para triunfar (siempre materialmente hablando).

El éxito de esta forma de ver el mundo se hace visible en los años ochenta, con la llegada al poder de Ronald Reagan y Margaret Thatcher, en Estados Unidos e Inglaterra respectivamente, pero su arquitectura comenzó a diseñarse mucho antes, y forma parte de una enorme y exitosa campaña de propaganda: nos referimos a esas factorías de pensamiento y comunicación denominadas thinks tanks, como la Randon Corporation, el Proyecto para un Nuevo Siglo Americano, etc, que prepararon el terreno, especialmente desde el punto de vista ideológico para que el pueblo americano ( $y$, posteriormente, todo el mundo) aceptase unos gobiernos que irían directamente en contra de sus intereses: de las ayudas sociales o de las conquistas sindicales, considerados por aquéllos como "ayuda a los vagos".

Desde luego, esta forma de ver las cosas tampoco parece la más adecuada para llenar el vacío existencial del que venimos hablando. Por ello, en muchos casos, la gente que venía de una tradición religiosa, se vuelca hacia las llamadas "teologías de sustitución" o Nuevos Movimientos Religiosos: sectas, religiones orientales de todo tipo, la New Age, etc, produciéndose en muchos casos una verdadera degradación del espíritu religioso, cuando se 
cae en la frecuentación de técnicas adivinatorias, pseudoterapias o libros de autoayuda, que vienen a confirmar el diagnóstico de Ignacio Ramonet (1997: 117 y ss) cuando dice que en estos tiempos contemplamos un nuevo "ascenso de lo irracional".

El otro yacimiento de sentido, de legitimación hacia el que se dirige, o es dirigida, una ingente cantidad de personas, y que está estrechamente vinculado con la ideología triunfante, es el consumo, al que no podemos separar de lo que en principio era un instrumento y ahora se ha convertido en un elemento constitutivo $e$ insustituible del sistema: la publicidad.

Aunque pueda parecer un juego de palabras, lo cierto es que se ha intentado llenar un vacío espiritual con el consumo materialista. Hacemos aquí hincapié en el hecho de que el tema de la búsqueda del sentido está estrechamente ligado con ese vacío connatural al hombre. Pues bien, desde una postura a la que podríamos llamar anti-metafórica, el capitalismo nos ofrece "Ilenar" literalmente ese vacío con el consumo de objetos materiales, cuantos más, mejor

La paradoja de satisfacer una necesidad espiritual con un recurso material la resuelve el capitalismo poniendo en práctica dos mecanismos. Primero, haciendo aquello que ya había predicho Marx: sustituyendo el valor de uso de los objetos por un valor añadido y, a menudo, divorciado del primero: el valor de cambio. El predominio del valor de cambio consigue suprimir el recuerdo del valor de uso originario, con lo cual, dice Mike Featherstone (2000: 41), la mercancía queda en condiciones de recibir valores sucedáneos, "recogiendo una amplia gama de asociaciones e ilusiones culturales". Y aquí es donde nos encontramos con el segundo recurso al que aludíamos más arriba: la comunicación persuasiva, ya que, como sigue diciendo el autor citado:

\footnotetext{
La publicidad, en particular, es capaz de explotar este fenómeno y asociar imágenes de romanticismo, exotismo, deseo, belleza, plenitud, comunalidad, progreso científico y de la vida buena a bienes de consumo mundanos tales como jabones, máquinas de lavar, automóviles y bebidas alcohólicas.
}

La publicidad, por tanto, tal y como lo advertía Raúl Eguizábal, actúa en el papel de discurso al servicio de una estructura de poder concreto: el sistema capitalista posindustrial, neoliberal, o como quiera llamárselo, que ha entronizado el consumo como única instancia a la que muchas personas pueden recurrir para satisfacer sus necesidades de trascendencia.

Con ello, ha contribuido, primero, a que la maquinaria productiva siga funcionando gracias a la demanda producida por la generación del deseo de consumo y, segundo, a suplantar o reducir a su mínima expresión las distintas opciones alternativas al capitalismo salvaje, las que, ya por las circunstancias históricas, ya por la dejación personal, han perdido una de sus principales bazas: la propuesta de una visión del mundo y del hombre opuesta a la razón cuantificadora y el beneficio personal. 
La jugada maestra del capitalismo ha sido la de crear, mediante la publicidad, un simulacro, un sucedáneo, de sentido, valores espirituales, trascendentes y legitimadores, convenciendo a la gente de que sólo podrá alcanzar esos objetivos haciendo precisamente lo contrario de lo que esos valores representan, es decir, consumiendo y acumulando cantidades ingentes de objetos, a menudo, completamente innecesarios.

La publicidad se ha convertido en el nuevo Evangelio de la posmodernidad, cuyo mensaje es que ya podemos alcanzar la felicidad puesto que todo lo que nos hace falta lo encontraremos en la planta de oportunidades del hipermercado de turno que, además, y como propina a la "buena nueva", nos anuncia que sus puertas permacerán abiertas los días domingo y festivos del mes de diciembre.

Consumo y publicidad, pues, como neorreligión, como elemento sustitutivo de lo sacro. Ya nos lo advertía el citado Featherstone (2000: 83):

Como observaba Durkheim, si cualquier cosa puede volverse sagrada, ¿por qué no los bienes "profanos" del capitalismo? Si se atiende al uso real que se hace de las mercancías, se ve con claridad que en determinados contextos pueden perder su condición de tales y asumir una carga simbólica (...) que las convierte en sagradas para sus usuarios. Por tanto, es posible que los bienes de consumo mundano pasen a ser posesiones veneradas.

Calmar la angustia, reforzar nuestra seguridad personal, conjurar la amenaza de la muerte (u olvidarla por un rato), proporcionarnos una percepción más euforizante de la vida, son funciones que Pérez Tornero (1992) atribuye al consumo pero que, desde siempre, fueron privativas de la religión.

Ahora se las ha apropiado el capitalismo y las ha impuesto, en este nuevo formato, al imaginario social merced a la publicidad que, de este modo, ha adquirido "vida propia", por así decirlo, es decir, que ya no es sólo un mero instrumento al servicio de un sistema, sino que se ha convertido en su piedra angular. Como dice Eguizábal (2007:204):

Con el paso de los años, la publicidad se convierte en el discurso dominante, en la forma de comunicación absoluta: garantiza el flujo de dinero a productores de mercancías y medios de comunicación, asegura la transmisión de la ideología y la conservación del statu quo (...) Una marca no es simplemente un hecho económico, es un hecho cultural, un suceso ideológico.

Precisamente por ello le ha sido posible introducir los objetos en el territorio de lo sagrado y elevar el consumo a la categoría de religión, especialmente para aquellos a los que el sistema ha excluido y arrojado a los márgenes (a la marginación), aquellos que necesitan "agarrarse" a algo, y sólo encuentran esta nueva teología de sustitución que es el culto al objeto, (conseguido, como dice atinadamente Juan Rey, en esos altares laicos llamados shopping center), objeto cuya posesión proporciona a muchas personas "una ingenua sensación de poderío" porque, como sigue afirmando Raúl Eguizábal (2007: 209) con implacable lucidez: “Cuando más fracasados, humillados e insatisfechos, más necesidad tienen de consumir. Los mayores niveles de consumo (con respecto a los ingresos) se producen en las capas sociales más desfavorecidas". Aquellas, agregamos nosotros, también 
proclives a caer en la telaraña de una secta, de la piedad cósmica, de la New Age, o de la consulta a patéticas adivinas televisivas.

Ahora bien, el hecho de que hablemos de una sacralización del consumo y una sustitución de la religión por el discurso publicitario no debe llamarnos a equivocación. Más allá de las semejanzas, del uso de estrategias persuasivas similares, etc., existe una diferencia fundamental que no debemos olvidar y que nos recordaba Juan Rey en el texto citado más arriba: consumo y publicidad se asocian a valores materiales mientras que la religión remite al plano de lo espiritual.

Quiere ello decir que, por más que la publicidad dote a los objetos de sobresignificaciones simbólicas que los introducen en el espacio de lo sagrado, por mucho que el propio discurso publicitario aluda a imágenes arquetípicas enraizadas en nuestro inconciente colectivo, por más que nos prometan el paraíso en la tierra, al final del recorrido, es decir, en las cajas del supermercado o en los vertederos de basura, desembocaremos en la materia pura y dura, una materia que, entre otras cosas, pertenece al reino de la cantidad, lo cual la sitúa en las antípodas del espíritu.

Lo hemos dicho: el capitalismo lo convierte todo en mercancía, inclusive los valores, que también cotizan en el mercado. Para que el capitalismo funcione requiere que todo sea cuantificable y mensurable. Como dice Featherstone (2000: 40), la acumulación de bienes y el triunfo del valor de cambio “...torna posible un cálculo racional instrumental de todos los aspectos de la vida, por el que todas las diferencias esenciales, las tradicionales y las cualidades culturales se transforman en cantidades" ¿Cómo lo consigue? La respuesta es: ideología, en su tercera acepción, es decir, falsa conciencia. Mediante la publicidad, el capitalismo tardío oculta esta cuantificación alienante de nuestras vidas con el velo ilusorio de los signos ya que en este sistema, sigue diciendo el autor antes citado (40-41): “El signo y la mercancía se han reunido para producir el "signo-mercancía", lo cual ha desembocado en la autonomía del significante "alcanzada a través de la manipulación en los medios de comunicación y la publicidad"

Esa es la gran ilusión que nos vende (en sentido literal) el sistema: cuanto más objetos compremos, más plenitud y más confort espiritual. Pero el consumo se parece peligrosamente a los estupefacientes: su efecto euforizante no dura mucho tiempo, de hecho, a poco de abandonar el shopping ya comienza el síndrome de abstinencia, lo cual nos obliga a volver lo antes posible, a por más droga. En este sentido, la economía del espíritu es muy superior, tanto por los resultados como por la duración de sus efectos.

Pero el enorme poder del que ha sido investida la publicidad al operar la metamorfosis del objeto en valores con resonancias pseudoreligiosas, y posibilitar el funcionamiento del sistema, no sólo la ha convertido en el discurso dominante sino que la ha llevado a colonizar otros aspectos de la vida social, de manera que su influencia se hace sentir de forma determinante en el terreno del ocio y los deportes, en los procesos de socialización y de 
creación de identidad (especialmente entre niños y jóvenes), en el arte, especialmente, en el cine, y en la política.

En este último caso, la publicidad ha impuesto sus estrategias persuasivas y sus operaciones sígnicas al discurso político, a la antigua propaganda y a los propios actores. El político o el candidato a algún cargo, recibe un tratamiento similar al que se da a cualquier objeto de consumo: sometimiento a las leyes de la oferta la demanda, tratamiento simbólico para atribuir al objeto unos determinados valores, aquellos que según los estudios del mercado electoral demandan los votantes, preeminencia de la imagen y las emociones suscitadas por ella por encima del discurso argumentativo y racional, etc.

El marketing político sustituye a la propaganda, puesto que ésta nos recuerda otros tiempos, aquellos en que el autoritarismo y las ideologías totalitarias imperaban en la Europa de primera mitad del siglo XX. Lo que ha ocurrido es que nos hemos ido al otro extremo, al de la posmodernidad, que rechaza cualquier explicación del mundo que "huela a ideología", donde ideología es el término utilizado para descalificar el pensamiento heredero de la Ilustración. Se rechaza también, con la excusa de que alude a los tiempos de Hitler o Stalin, cualquier noción de jerarquía o autoridad, incluida la de la razón, con lo cual se instaura una especie de "todo vale", que es el clima perfecto para la circulación del discurso hegemónico, el del consumo, el del todopoder del mercado y el beneficio a cualquier precio.

De todas maneras, esta primera década del siglo XXI parece dar algunas señales de nostalgia de la cordura y de deseo de luchar contra la entropía mercantil posmoderna que va camino de acabar con el planeta. Se traduce ello en un discurso que busca recuperar el prestigio robado a la razón, y podemos verlo en los títulos de algunos libros como el de Al Gore: El ataque contra la razón (2007) o el que anuncia el politólogo y periodista Joseph Ramoneda: Defensa apasionada de la Ilustración (2007).

Sólo nos queda esperar que no hayan llegado demasiado tarde 


\section{REFERENCI AS BIBLI OGRÁFICAS}

DıJK, Teun Van (1998): I deología. Barcelona, Gedisa.

EAGLETON, Terry (1997): Ideología. Una introducción. Barcelona, Paidós.

EGUIZÁBAL, Raúl (2007): Teoría de la publicidad. Madrid, Cátedra.

FeAtherstonE, Mike (2000): Cultura de consumo y posmodernismo. Buenos Aires, Amorrortu.

FERRY, Luc y GAUCHET, Marcel (2007): La religión después de la religión. Barcelona, Anthropos.

FREUD, Sigmund (2002): Introducción al psicoanálisis. Madrid, Alianza.

GINER, Salvador (1994): “La religión civil”, en Rafael DíAZ SALAZAR: Formas Modernas de religión. Madrid, Alianza, pp. 129-171.

GoRE, Al (2007): El asalto a la razón. Barcelona, Debate.

LAPLANTINE, François (1977): Las tres voces de la imaginación colectiva. Barcelona, Granica.

LENOIR, Frédéric (2005): Las metamorfosis de Dios. Madrid, Alianza.

MARDONES, José Mạ (2000): Nuevas formas de religión. Estella, Verbo Divino.

Moro, T., Campanela, T. y Bacon, F. (1992): Utopías del Renacimiento. México, F.C.E.

Pérez Tornero, José M. (1992): La seducción de la opulencia. Barcelona, Paidós.

PizARRoso, Alejandro (1995): Historia de la propaganda. Madrid, EUDEMA.

RAMONEDA, J oseph (2007): Defensa apasionada de la Ilustración. Barcelona, Gedisa.

RAMONET, I gnacio (1997): Un mundo sin rumbo. Madrid, Temas de Debate.

REY, Juan (2006): “Publicidad y religión. Semejanzas y diferencias entre el discurso Publicitario y el discurso católico" en Trípodos, no 18, pp. 65-94.

RicoeUR, Paul (1990): Ideología y utopía. Barcelona, Gedisa.

TAMAYO, Juan J osé (1987): Cristianismo: profecía y utopía. Estella, Verbo Divino.

TRousson, Raymond (1999): Historia de la literatura utópica. Viajes a países Inexistentes. Barcelona, Península.

Weber, Max (2000): Ensayos sobre sociología de la religión, (3 vols). Madrid, Taurus.

[Recibido: 14-11-2007. Aceptado: 14-12-2007] 